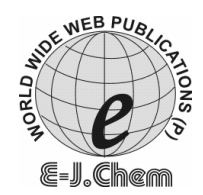

\title{
Adsorption of Crystal Violet Dye onto Tamarind Seed Powder
}

\author{
HIMANSHU PATEL ${ }^{*}$ and R.T. VASHI \\ Department of Chemistry, \\ Navyug Science College, Rander Road, Surat-395009, India. \\ hjpatell23@yahoo.in
}

Received 11 November 2009; Accepted 5 January 2010

\begin{abstract}
The present investigation describes adsorption of crystal violet dye from its aqueous solution onto tamarind (Tamarindus indica) fruit shell powder. Initial concentration, agitation speed and $\mathrm{pH}$ with various temperature have been studied, in which $\mathrm{pH}$ was found to be most effective. The adsorption data were mathematically analyzed using adsorption isotherm like Freundlich and Langmuir isotherm to study adsorption mechanism of crystal violet onto this seed powder. Freundlich isotherm was found to be most applicable. The equilibrium data were applied to intra-particle diffusion and adsorption kinetics. The reaction was found to be pseudo second order.
\end{abstract}

Keywords: Tamarind,Crystal violet, Langmuir, Freundlich isotherm.

\section{Introduction}

Textile industry uses large volumes of water in wet processing operations and thereby, generates substantial quantities of wastewater containing large amounts of dissolved dyestuffs and other products, such as dispersing agents, dye bath carriers, salts, emulsifiers, leveling agents and heavy metals ${ }^{1}$. Majority of this dyes are synthetic in nature and are usually composed of aromatic rings in their structure, inert and non-biodegradable when discharged into waste streams. Therefore, the removal of such colored agents from aqueous effluents is of significant environmental, technical and commercial importance ${ }^{2}$. Highly colored wastes are not only aesthetically displeasing but also hinder light penetration and may in consequence disturb biological processes in water-bodies. Moreover, dyes itself are toxic to some organisms and hence disturb the ecosystem. In addition, the expanded uses of dyes have shown that some of them and their reaction products such as aromatic compounds are highly carcinogenic, which make the removal of dyes before disposal of the wastewater is necessary ${ }^{3}$.

The studies have been performed in order to remove color and other contaminations using various types of methods include adsorption ${ }^{4}$, coagulation ${ }^{5}$, nano-filtration and ozonalysis $^{6}$, membrane filtration ${ }^{7}$, oxidation process ${ }^{8}$ etc., in which adsorption is most useful due to its efficiency and visibility. The use of low-cost, easy obtained, high efficiency and eco-friendly adsorbents has been investigated as an ideal alternative to the current expensive 
methods of removing dyes from wastewater. These adsorbents were prepared from natural materials such as plant roots, leaf and seed like neem leaf powder ${ }^{10,11}$, gulmohar plant leaf powder $^{12}$, shells of hazelnut and almond ${ }^{13}$, shells of lentil, wheat and rice ${ }^{14}$, orange pee ${ }^{15}$, Banana peel ${ }^{16}$, guava leaf powder ${ }^{17}$ used for removal of color.

Investigations were carried to adsorb different types of metals on tamarind seed powder ${ }^{18-20}$. Also, it is evident that, they were utilized to adsorb crystal violet $(\mathrm{CV})$ using various types of adsorbents ${ }^{21-23}$.

The present study was performed to investigate the surface morphology of tamarind seed powder (TSP) using various methods viz. particle size, FT-IR spectroscopy and SEM analysis and exploitation for removal of $\mathrm{CV}$ from aqueous solution. The parameters such as $\mathrm{pH}$, contact duration and adsorbent dosage with different temperature were studied. Adsorption isotherm (Freundlich and Langmuir) and adsorption kinetics (Pseudo first-, second-order and intra particle diffusion) were also analyze in this explored.

\section{Experimental}

The tamarind, a family of Fabaceae, has used for preparation of medicines for internal and external applications and as condiment in many dishes. The major application of seed is commonly lies in the manufacturing of textile sizing powder. Tamarind fruit seed, collected near Navyug Science College, Gujarat and a waste product of tamarind pulp, are washed, dried and pulverized. This powder was further washed with distilled water till the washings were free of color and turbidity and then after, dried in the oven for $2 \mathrm{~h}$ at $60^{\circ} \mathrm{C}$. Sympatic, Germany (Model: Helos-BF) was use to analyze the TSP particle size. The Fourier transform analysis was carried out using instrument Shimadzu, Japan (Model: 8400 S) at wave length of 400-4 $000 \mathrm{~cm}^{-1}$. SEM image were taken using Philips, The Netherlands (Model: XL-30 ESEM).

\section{Adsorbate}

The dye, crystal violet (CI 42555, Class: basic dye 3) having chemical formula: $\mathrm{C}_{25} \mathrm{H}_{30} \mathrm{~N}_{3} \mathrm{Cl}$ and molecular mass: $407.98 \mathrm{~g} / \mathrm{mol}$, used in this study was supplied by Merck, India. Structure of crystal violet molecule is shown in Figure 1.<smiles>CN(C)c1ccc(C(=C2C=CC(=[N+](C)Cl)C=C2)c2ccc(N(C)C)cc2)cc1</smiles>

\section{Experimental details}

Figure 1. Structure of crystal violet.

Effect of initial concentration was studied by treatment $\mathrm{CV}$ solutions containing different concentration (2.0 to $14 \times 10^{-6} \mathrm{M}$ ) with TSP at shaking speed of $300 \mathrm{rpm}$ at different temperatures of 310,320 and $330 \mathrm{~K}$. To determine the effect of different agitation speed, the $\mathrm{CV}$ solution (concentration: $6.0 \times 10^{-6} \mathrm{M}$ ) was treated with TSP at different temperatures of 310,320 and $330 \mathrm{~K}$ and different agitation speed i.e. 100 to $1000 \mathrm{rpm}$. pH studied was conducted by treating TSP was treated with TSP at range of $\mathrm{pH}$ values from 3 to 11 at shaking speed of 300 $\mathrm{rpm}$. The $\mathrm{pH}$ of the solutions was adjusted with $1 \mathrm{~N} \mathrm{HCl}$ or $\mathrm{NaOH}$ solution by using a $\mathrm{pH}$ meter. 
All the above experiments were carried out at adsorbent (TSP) dosage of $5.0 \mathrm{~g} / \mathrm{mL}$ and time duration at $4 \mathrm{~h}$. The concentration of the dye was measured by a spectrophotometer (ELICO SL 164 Double Beam UV-VIS Spectrophotometer) at $\lambda_{\max }=584 \mathrm{~nm}$ and percentage of removal and quantity of dye adsorbed, $\mathrm{q}_{\mathrm{e}}(\mathrm{mol} / \mathrm{g})$ was calculated using the following formula:

$$
\begin{aligned}
\% \text { Removal } & =\left(\mathrm{C}_{\mathrm{o}}-\mathrm{C}_{\mathrm{e}}\right) \times 100 / \mathrm{C}_{\mathrm{o}} \\
\mathrm{q}_{\mathrm{e}} & =\left(\mathrm{C}_{\mathrm{o}}-\mathrm{C}_{\mathrm{e}}\right) \times \mathrm{V} / \mathrm{W}
\end{aligned}
$$

Where, $C_{o}$ and $C_{e}$ are initial and equilibrium concentration of dye respectively. $V$ the volume of the solution and $\mathrm{W}$ the weight of the TSP used.

\section{Adsorption isotherm}

The analysis and design of adsorption separation processes requires the relevant adsorption equilibria, which is the most important piece of information in understanding an adsorption process. It is also important for designing an adsorption system. The adsorption equilibrium indicates how the adsorbate molecules distribute between the liquid phase (solution) and the solid phase (adsorbent) when the adsorption process reaches an equilibrium state. To describe the adsorption equilibrium data of crystal violet dye on adsorbent, TSP, Langmuir and Freundlich isotherm models were used. The Freundlich isotherm can be efficient on multilayer and also, heterogeneous surface and is expressed by the following equation.

$$
\mathrm{q}_{\mathrm{e}}=\mathrm{K}_{\mathrm{F}} \mathrm{C}_{\mathrm{e}}{ }^{1 / \mathrm{n}} \text { or } \log \mathrm{q}_{\mathrm{e}}=\log \mathrm{K}_{\mathrm{F}}+1 / \mathrm{n} \log \mathrm{C}_{\mathrm{e}}
$$

Where, $\mathrm{q}_{\mathrm{e}}$ and $\mathrm{C}_{\mathrm{e}}$ is the amount of adsorbed adsorbate per unit weight of adsorbent and unadsorbed adsorbate concentration in solution at equilibrium, respectively and $K_{F}$ and $1 / n$ are Freundlich constant characteristics of the system, which are determined from the log $\mathrm{q}_{\mathrm{e}}$ vs. $\log \mathrm{C}_{\mathrm{e}}$. Also, Langmuir adsorption is very useful for predicting adsorption capacities and also interpreting into mass transfer relationship. The isotherm can be written as follows:

$$
\mathrm{q}_{\mathrm{e}}=\mathrm{q}_{\mathrm{m}} \mathrm{Q}_{0} \mathrm{C}_{\mathrm{e}} /\left(1+\mathrm{b} \mathrm{C}_{\mathrm{e}}\right) \text { or }\left(\mathrm{C}_{\mathrm{e}} / \mathrm{q}_{\mathrm{e}}\right)=\left(1 / \mathrm{Q}_{0}\right)+\left(\mathrm{b} / \mathrm{K}_{\mathrm{L}}\right) \mathrm{C}_{\mathrm{e}}
$$

Where, $\mathrm{Q}_{\mathrm{o}}$ and $\mathrm{b}$ were the Langmuir constants, which measures of monolayer (maximum) adsorption capacity (in $\mathrm{mg} / \mathrm{g}$ ) and energy of adsorption (in $\mathrm{g} / \mathrm{L}$ ) respectively. The Langmuir parameters were obtained from the linear correlations between the values of $\mathrm{C}_{\mathrm{e}} / \mathrm{q}_{\mathrm{e}}$ and $\mathrm{C}_{\mathrm{e}}{ }^{24}$.

\section{Adsorption kinetics}

In order to investigate the mechanism of adsorption and potential rate controlling steps such as mass transport and chemical reaction processes, kinetic models have been used to test experimental data. These kinetic models include the pseudo-first-order equation, pseudosecond-order equation, and intraparticle-diffusion equation. The pseudo first-order equation of Lagergren is given by

$$
\ln \left(\mathrm{q}_{\mathrm{e}}-\mathrm{q}_{\mathrm{t}}\right)=\ln \mathrm{q}_{\mathrm{e}}-\mathrm{k}_{1} \mathrm{t}
$$

Where $q_{t}$ and $q_{e}$ are the amounts of TBC adsorbed at time $t$ and equilibrium $(\mathrm{mg} / \mathrm{g})$, respectively, and $\mathrm{k}_{1}$ is the pseudo first-order rate constant for the adsorption process $(1 / \mathrm{min})$. The linear graph of $\ln \left(\mathrm{q}_{\mathrm{e}}-\mathrm{q}_{\mathrm{t}}\right)$ vs. $\mathrm{t}$ shows the applicability of first order kinetic. Also, the pseudo second-order chemtisorption kinetic rate equation 5 is expressed as

$$
\mathrm{t} / \mathrm{q}_{\mathrm{t}}=1 / \mathrm{k}_{2} \mathrm{q}_{\mathrm{e}}^{2}+\left(1 / \mathrm{q}_{\mathrm{e}}\right) \mathrm{t}
$$

Where $\mathrm{k}_{2}$ is the equilibrium rate constant of pseudo second order equation $(\mathrm{g} / \mathrm{mg} \mathrm{min})$. The linearity of $t / q_{t} v s$. $t$ suggests the best fitted with pseudo second order kinetic. The kinetic data can also be analyzed by an intra-particle diffusion kinetic model, formulated as

$$
\mathrm{q}_{\mathrm{t}}=\mathrm{k}_{\mathrm{p}} \mathrm{t}^{1 / 2}+\mathrm{C}
$$


Where $\mathrm{k}_{\mathrm{p}}\left(\mathrm{mg} \cdot \mathrm{g}^{-1}\right.$.minute $\left.\mathrm{e}^{-1 / 2}\right)$ is the intra-particle diffusion rate constant and $C$ is the intercept of the plot of $\mathrm{q}_{\mathrm{t}}$ versus $\mathrm{t}^{1 / 2}$. If this linear plot passes through the origin, then intraparticle diffusion is the rate-controlling step. The plots of intra-particle diffusion do not passed through the origin ${ }^{25}$.

\section{Results and Discussion}

\section{Surface morphology of TSP}

The particle size of TSP was observed to be $100-120 \mu \mathrm{m}$ (Average: $110 \mu \mathrm{m}$ ), which is used as adsorbent in many experiments ${ }^{2,26}$. Figure 2 depicted FT-IR spectra of TSP, in which the bend near bend near $3600 \mathrm{~cm}^{-1}$ was revealed, is due to hydroxyl group, a broad bend near $3000-3200 \mathrm{~cm}^{-1}$ of amino and carboxylic acid group, a 1653 and $1541 \mathrm{~cm}^{-1}$ are due to primary amine and nitro compound and also, $1064 \mathrm{~cm}^{-1}$ of primary alcohol (C-O) stretching. The adsorbent containing these bends are usually utilized for color removal ${ }^{27,28}$. The SEM images of TSP (Figure 3) at higher magnifications 350X and 500X shows that the surface of materials is porous.

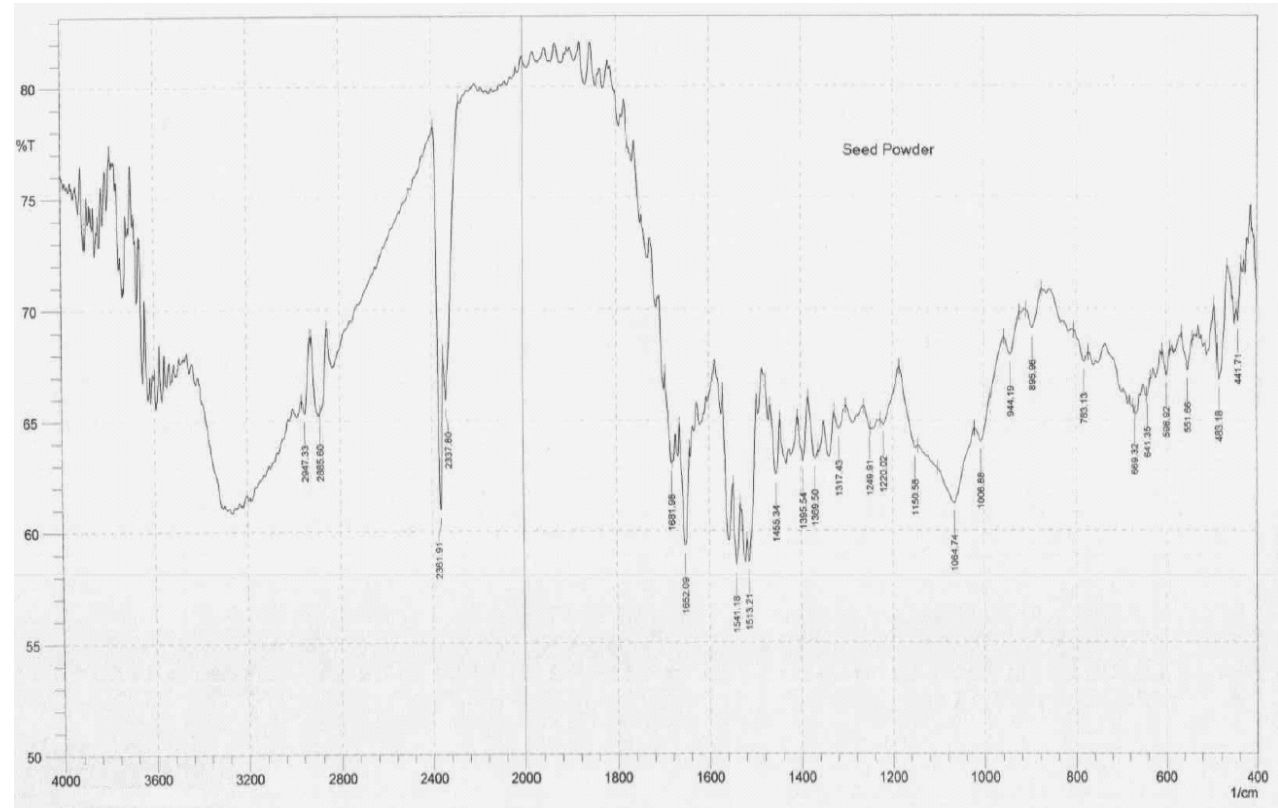

Figure 2. Depicted FTIR spectra of TSP.
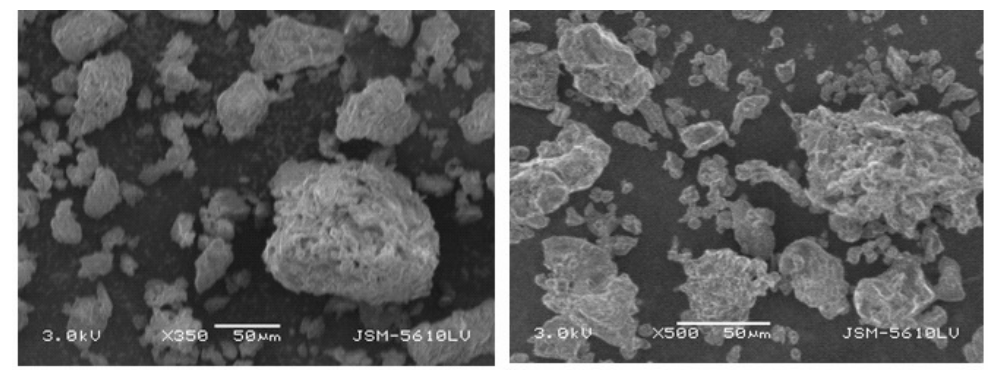

Figure 3. SEM images of TSP. 


\section{Effect of initial concentration}

Figure 4 depicted the effect of initial concentration with different temperature ranges. It shows the percentage removal of dye decreases from $8.6 \%$ up to $65.4 \%$ with an increase of initial concentration even though adsorption density increases. The mass of the given adsorbent can adsorb only a fixed amount of dye. Therefore, the more concentrated an effluent, the smaller is the volume of effluent that a fixed mass of adsorbent can purify ${ }^{22}$. Also, it was observed that sorption of TSP for CV increased with increasing temperature indicating that the sorption process was endothermic in nature. The increase in uptake of dye molecules with temperature may be due to the desolvation of the sorbing species and change in the size of the pores and further evidence that intraparticle diffusion plays an important role in the rate-determining step in the adsorption of CV on TSP is confirmed by the temperature dependence of the rate of adsorption ${ }^{2}$.

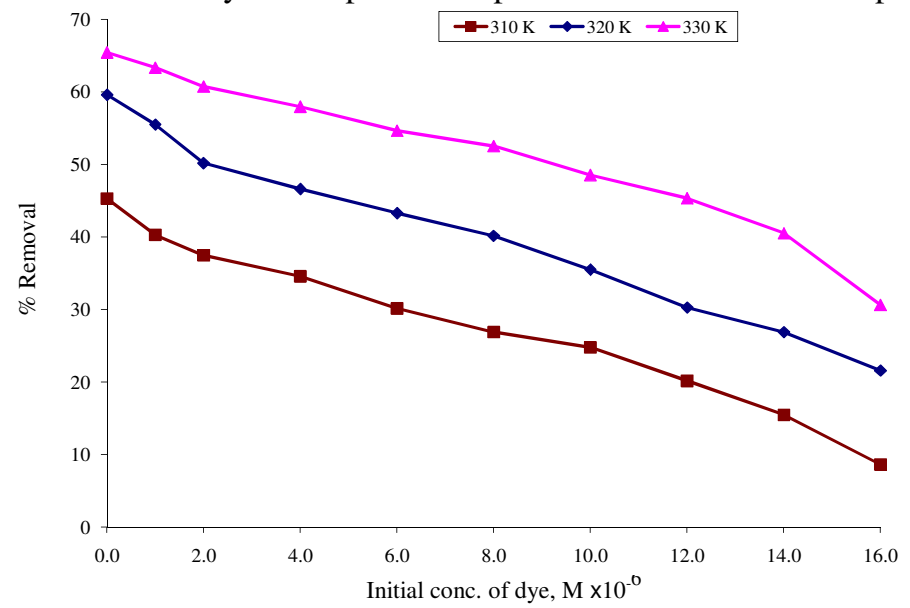

Figure 4. Effect of initial concentration of TSP with different temperatures.

\section{Effect of agitator speed}

The variation of percentage adsorption of $\mathrm{CV}$ with agitator speed and temperature at initial concentration of $\mathrm{CV}$ using concentration of $6.0 \times 10^{-6} \mathrm{M}$ and $\mathrm{pH}$ of 7.0 is shown in Figure 5. As agitator speed increases, percentage adsorption significantly also increases up to 15.5 to $50.0,20.5$ to 60.0 and 25.5 to $69.7 \%$ at 50 to $900 \mathrm{rpm}$ respectively with different temperatures $(310,320$ and $330 \mathrm{~K})$, but then gradually approaches a constant value after 900 $\mathrm{rpm}$. So, the equilibrium attained at $900 \mathrm{rpm}$ for adsorption of CV onto TSP. The mechanism of adsorbate removal involved four steps: (i) migration of adsorbate molecules from the bulk solution to the surface to the surface of the adsorbent; (ii) diffusion through the boundary layer to the surface of adsorbent; (iii) adsorption at a site; and (iv) intraparticle diffusion into the interior of the adsorbent. Increasing agitation speed decreases the boundary layer resistance of the transfer of adsorbate molecules from the bulk solution to the adsorbent surface. Due to this, the adsorbate is forced towards the adsorbent surface and leads to an increases in the diffusion of adsorbate into the surface of the adsorbent ${ }^{29}$. Further, it was verified that percentage of removal is increasing with increasing temperature.

\section{Effect of $p H$}

Figure 6 shows the dynamic adsorption of $\mathrm{CV}$ on TSP at different initial $\mathrm{pH}$ values with variable temperatures at initial dye concentration of $6.0 \times 10^{-6} \mathrm{M}$. When the $\mathrm{pH}$ is changed from 1 to 7 , the adsorption was slowly increase from 25.2 to $86.6 \%$ respectively and from 7 to 11 , it was drastic increased up to 63.3 to $95.5 \%$ respectively. For cationic dyes, lower adsorption of 
$\mathrm{CV}$ at acidic $\mathrm{pH}$ is probably due to the presence of excess $\mathrm{H}^{+}$ions competing with the cation groups on the dye for adsorption sites. As surface charge density decreases with an increase in the solution $\mathrm{pH}$, the electrostatic repulsion between the positively charged dye and the surface of the adsorbent is lowered, which may result in an increase in the extent of adsorption ${ }^{30}$. It was confirmed that when temperature of system was increases, adsorption also increasing.

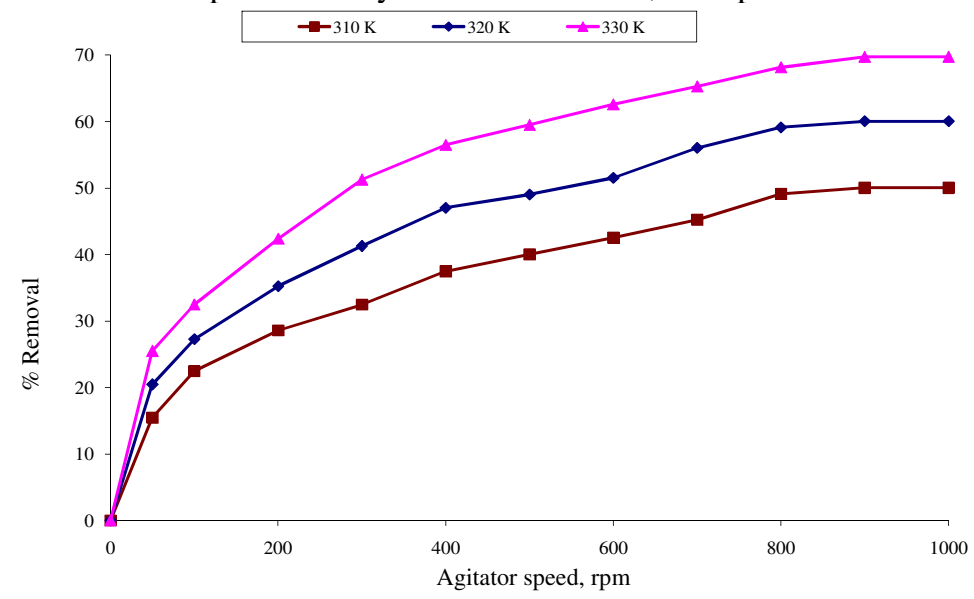

Figure 5. Effect of agitator speed with various temperatures.

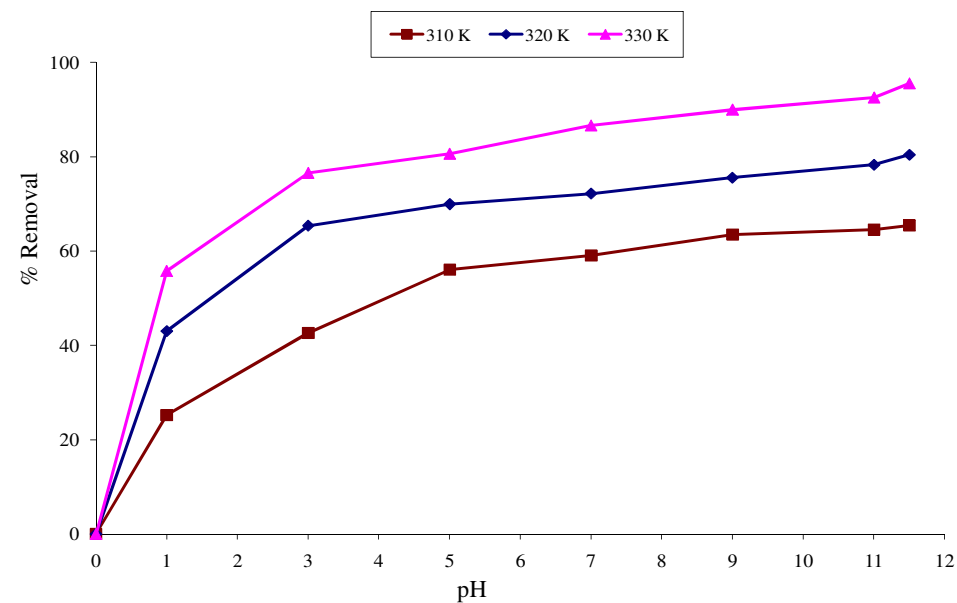

Figure 6. Effect of $\mathrm{pH}$ with different temperatures.

\section{Isotherm date analysis}

Figures 7 depicted the non-linear graph of amount of CV adsorbs $v s$. equilibrium concentration at dye concentration of $6.0 \times 10^{-6} \mathrm{M}$ at $\mathrm{pH} 7$ and agitator speed of $500 \mathrm{rpm}$ at temperatures of 310 and $320 \mathrm{~K}$. Experimental values obtained for Langmuir parameters i.e. adsorption capacity $\left(\mathrm{K}_{\mathrm{L}}\right)$ and intensity $\left(\mathrm{Q}_{\mathrm{o}}\right)$ and Freundlich parameters i.e. capacity $\left(\mathrm{K}_{\mathrm{F}}\right)$ and intensity $(\mathrm{n})$ are represented in Table 1. The correlation coefficient values obtained from the Freundlich and Langmuir isotherms are also presented. The values indicate that the adsorption pattern followed Langmuir isotherm then Freundlich isotherm. The same results were obtained by adsorption of dye from its aqueous solution onto different adsorbents ${ }^{31-33}$.

\section{Kinetic model}

The kinetic models, pseudo first-, second-order and intra-particle diffusion graphs were mentioned 
in Figures 8(a), (b) and (c) respectively. All straight line graphs suggested to follow all these kinetics model. Table 2 depicted the correlation coefficient $\left(r^{2}\right)$ values of kinetic models at different temperatures, indicates that pseudo second-order was greater than others two kinetics models, pseudo first-order and intra-particle diffusion for all temperatures. So, the results were best to pseudo second-order kinetic model. The trend was observed using various types of adsorbents ${ }^{34,35}$.

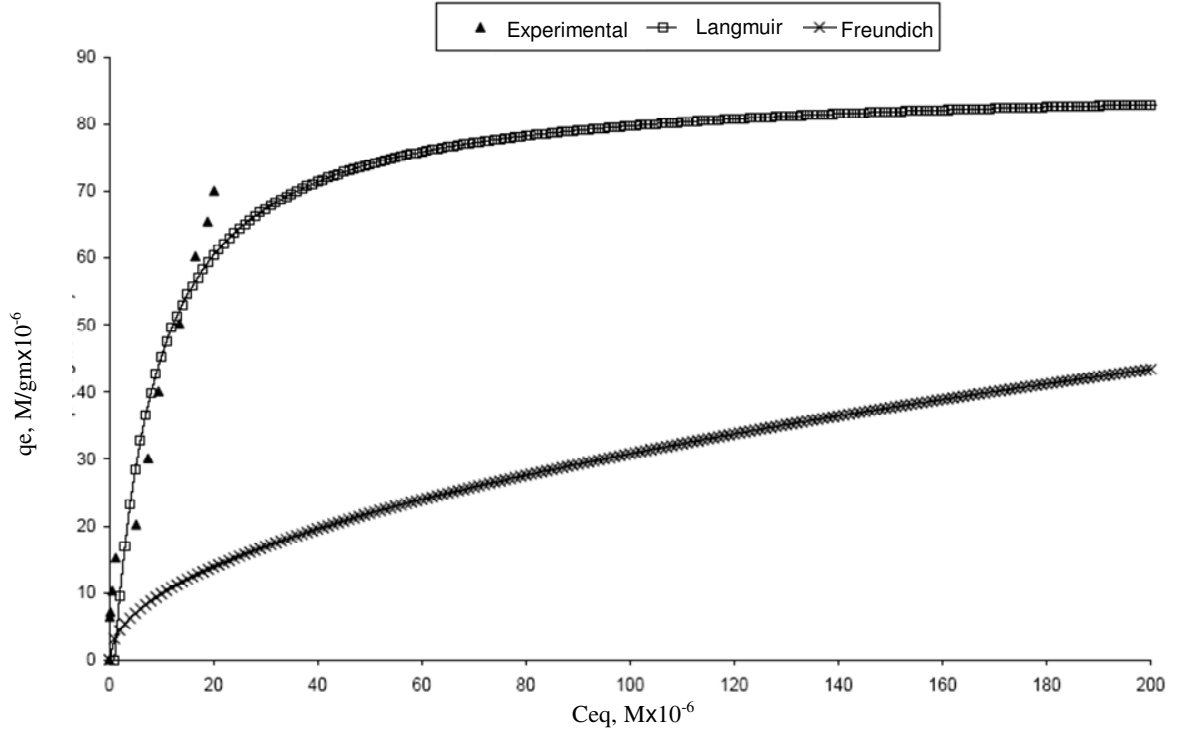

Figure 7. Non-linear graph of Freundlich and Langmuir isotherm.

Table 1. Isotherm parameters for adsorption of CV onto TSP.

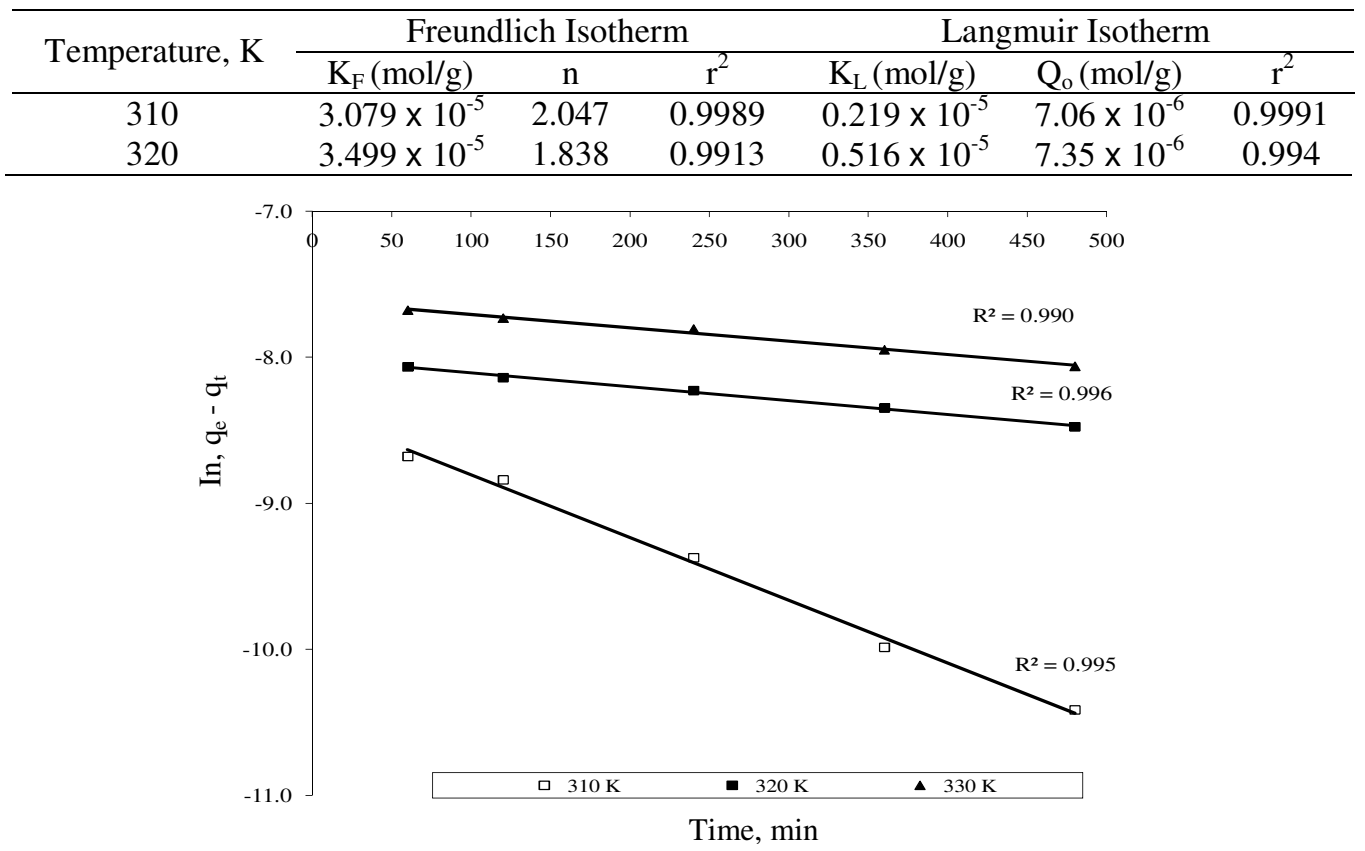

Figure 8 (a). Pseudo-first order equation. 


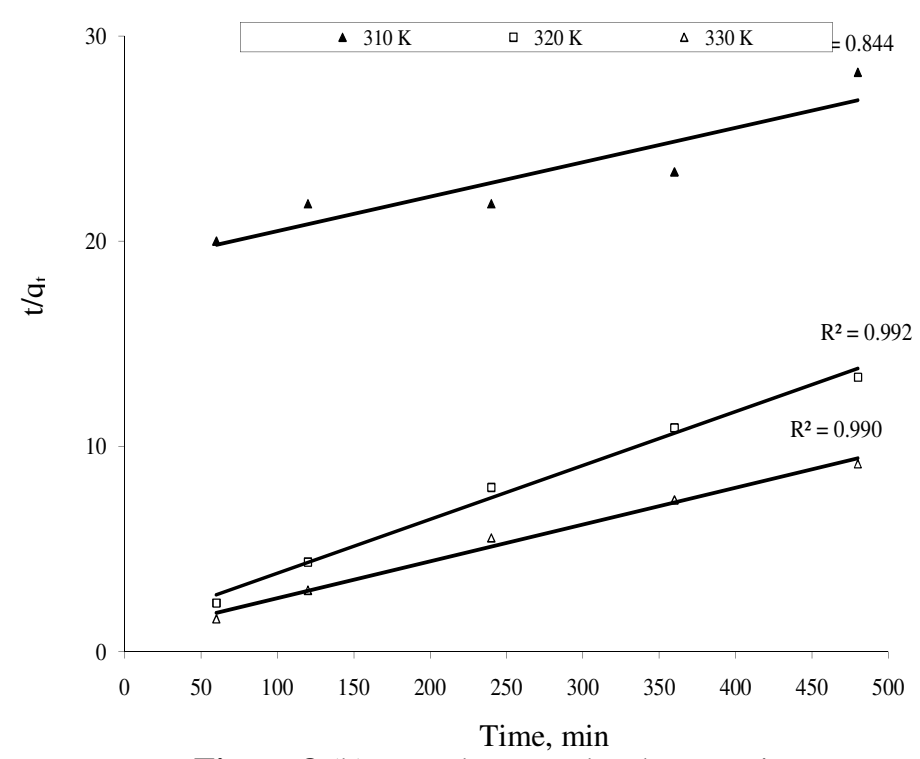

Figure 8 (b). Pseudo-second order equation.

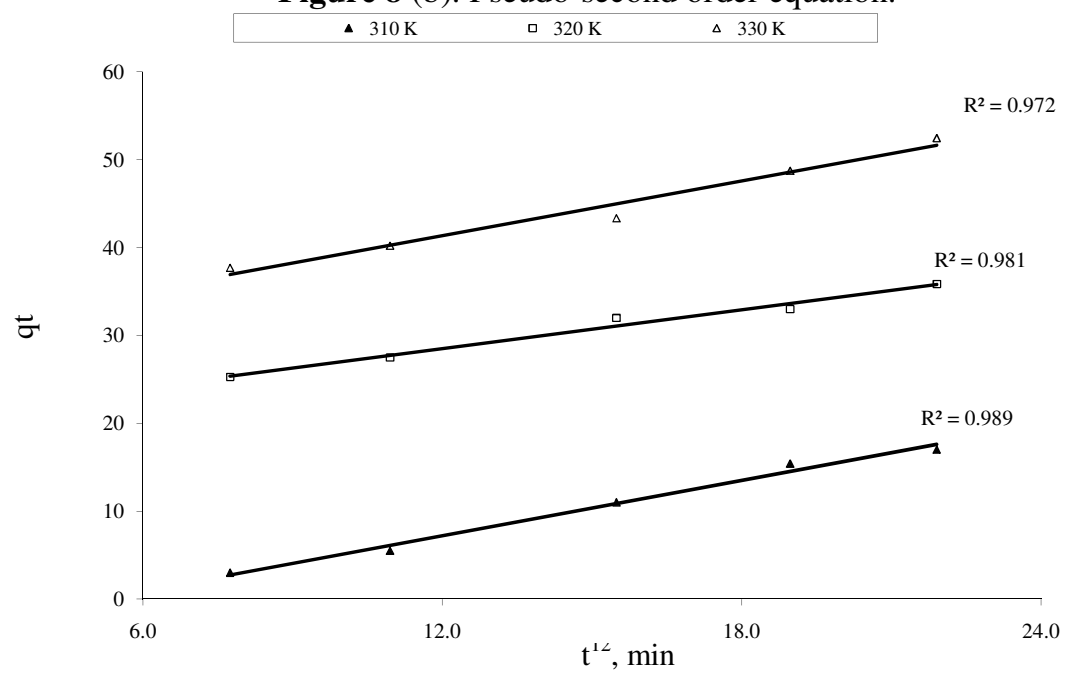

Figure 8 (c). Intra-particle diffusion equation.

Figure 8. Plots of adsorption kinetic equations for adsorption of TBC onto NLP at different contact duration, (a) pseudo first-order equation, (b) the pseudo second-order equation and (c) the Intra-particle diffusion equation.

Table 2. Kinetic parameters for the adsorption of CV onto TSP.

\begin{tabular}{ccccc}
\hline \multirow{2}{*}{ S. No. } & Temperature & \multicolumn{3}{c}{$\mathrm{r}^{2}$ Value } \\
\cline { 3 - 5 } & $\mathrm{K}$ & Pseudo first-order & Pseudo second-order & Intra-particle equation \\
\hline 1 & 310 & 0.9951 & 0.9907 & 0.9728 \\
2 & 320 & 0.996 & 0.992 & 0.9818 \\
3 & 330 & 0.9904 & 0.8446 & 0.9893 \\
\hline
\end{tabular}




\section{Conclusion}

A significant adsorption of Crystal Violet dye onto Tamarind Seed Powder was found using different variables like initial concentration, $\mathrm{pH}$ and adsorbent dosage with various temperature, in which $\mathrm{pH}$ was found to be most effective. The maximum removal of crystal violet is found to be $95 \%$ at $\mathrm{pH}$ of 11 maintaining parameters like adsorbent dosage, initial concentration of dye, temperature, which were $5 \mathrm{~g} / \mathrm{L}, 0.000005 \mathrm{M}$ and $323 \mathrm{~K}$ respectively. The isotherm models were analyzed using the Langmuir and Freundlich for equilibrium data and kinetic models, pseudo first- order, second-order model and intra-particle diffusion equation to describe the kinetic data. The adsorption capacities were obtained from Freundlich and Langmuir isotherm plot were $3.499 \times 10^{-5}$ and $0.516 \times 10^{-5} \mathrm{~mol} / \mathrm{g}$. From coefficient correlation $\left(\mathrm{r}^{2}\right)$, we concluded that the experimental data were well fitted with Langmuir adsorption isotherm model and pseudo second order kinetic model.

\section{References}

1. Khaled A, El Nemr A, El-Sikaily A and Abdelwahab O, Desalination, 2009, 238, 210-232.

2. Bulut E, Ozacar M and Sengil I A, J Hazard Mater., 2008, 154, 613-622.

3. El-Nemr A, Abdelwahab O, El-Sikaily A and Khaled A, J Hazard Mater., 2009, 161, 102-110.

4. $\quad$ Singh A K and Tiwari P N, Indian J Chem Technol., 2003, 10, 211-216.

5. Joo D J, Shin W S, Choi J H, June C S, Kim M C, Han M H, Ha T W and Kim Y H Dyes Pigments., 2007, 73, 59-64.

6. Bea-Pia A, Mendoza-Roca M, Roig-Alocover L, Iborra-Clar A, Iborra-Clar M I and Alaciana-Miranda M I, Desalination, 2003, 157, 81-86.

7. Galambos I I, Molina J M, Jaray P, Vatai G and Bekassy-Molner E, Desalination 2004, 162, 117-120.

8. Aslam M M, Baig M A, Hassan I, Qazi I A, Malik M and Saeed H, Electronic J Enviro Agric Food Chem., 2004, 3 (6), 804-811.

9. Hung Y, Lo H H, Wang L K, Taricska J R and Li K H, Volume 3: Physiochemical Treatment Processes, Edited by: Wang L K, Hung Y T and Shammas N K, The Humana Press Inc., Totowa, NJ, 2005, 752.

10. Wang S, Li H, Xie S, Liu S and Xu L, Chemosphere, 2006, 65, 82-87.

11. Venkateswarlu P, Ratnam M V, Rao D S and Rao M V, Int J Phys Sci., 2007, 2(8), 188-195.

12. Ponnusami V, Aravindhan R, Karthik N R, Ramadoss G and Srivastava S N, $J$ Environ Prot Sci., 2009, 3, 1-10.

13. Bulut $\mathrm{Y}$ and Tez Z, J Hazard Mater., 2007, 149, 35-41.

14. Aydin H, Bulut Y and Yerlikaya C, J Environ Manage., 2008, 87, 37-45.

15. Sivaraj R, Namasivayam C and Kadirvelu K, Waste Manage., 2001, 21, 105-110.

16. Annadura G, Ruey-shin J and Duu-Jong. L, J Hazard Mater., 2002, B92, 263-274.

17. Ponnusami V, Vikram S and Srivastava S N, J Hazard Mater., 2008, 152(1), 276-286.

18. Pehlivan E and Altu T, J Hazard Mater., 2008, 155(1-2), 378-384.

19. Popuri S R, Jammala A, Reddy K V N S and Abburi K, Electron J Biotechnol., 2007, 10 (3), 358-367.

20. Priya A J, Gajulapalli S R, Abburi K and Boddu V M, Biorem J., 2008, 12(3), 145 - 155

21. Ghosh D, Medhi C R, Solanki H, Purkait M K, J Environ Prot Sci., 2008, 2, 25-35.

22. Vinod V P and Anirudhan T S, Water Air Soil Poll., 2003, 150, 193-217.

23. Nagda G K and Ghole V S, Int J Environ Res., 2008, 2(4), 385-390. 
24. Ozacar M, Adsorption, 2003, 9, 125-132.

25. Budyanto S, Soedjono S, Irawaty W and Indraswat N, J Environ Prot Sci., 2008, 2, 72- 80.

26. Ozacar M and Sengil I A, J Hazard Mater, 2003, B98, 211-224.

27. Karadag D, Turan M, Akgul E, Tok S. and Aysegul F, J Chem Eng Data, 2007, 52, 1615-1620.

28. Ahalya N, Kanamadi R D and Ramchandra T V, Electron J Biotechnol., 2005, 3(3), 258-264.

29. Mane S M, Vanjara A K and Sawant M R, J Chin Chem Soc., 2005, 52(6), 1117-1122.

30. Wang S, Li H, Xie S, Li S and Xu L, Chemosphere, 2006. 65, 82-87.

31. Inbaraj B S and Sulochana N, Indian J Chem Technol., 2002, 9, 201-208.

32. Malarvizhi R and Sulochana N, J Environ Prot Sci., 2008, 2, 40-46.

33. Prahas D, Kartika Y, Indraswati N and Ismadji S, J Environ Prot Sci., 2008, 2, 1-10.

34. Gomez V, Larrechi M S and Callao M P, Chemosphere, 2007, 69, 1151-1158.

35. Alpat S K, Ozbayrak O, Alpat S and Akcay H, J Hazard Mater, 2008, 151, 213-220. 


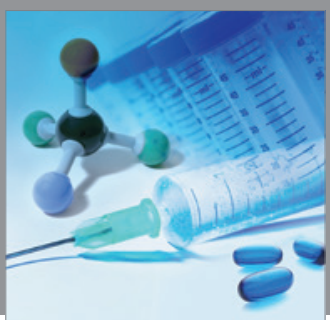

International Journal of

Medicinal Chemistry

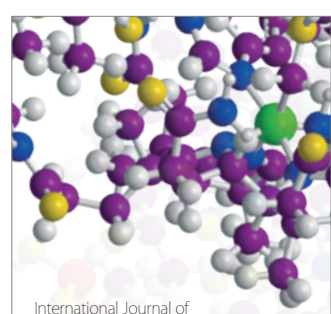

Carbohydrate Chemistry

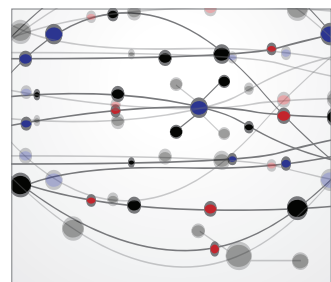

The Scientific World Journal
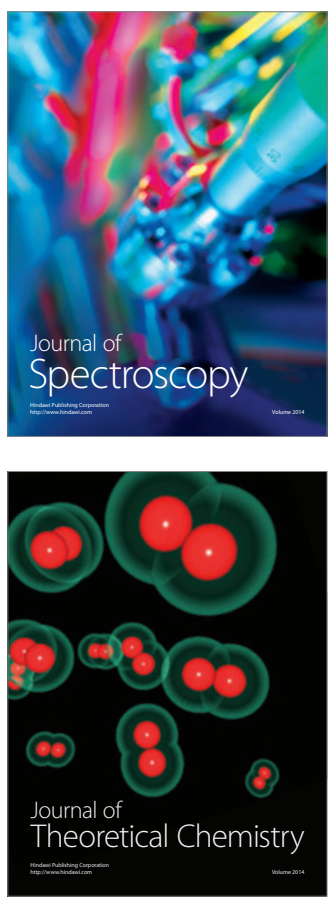
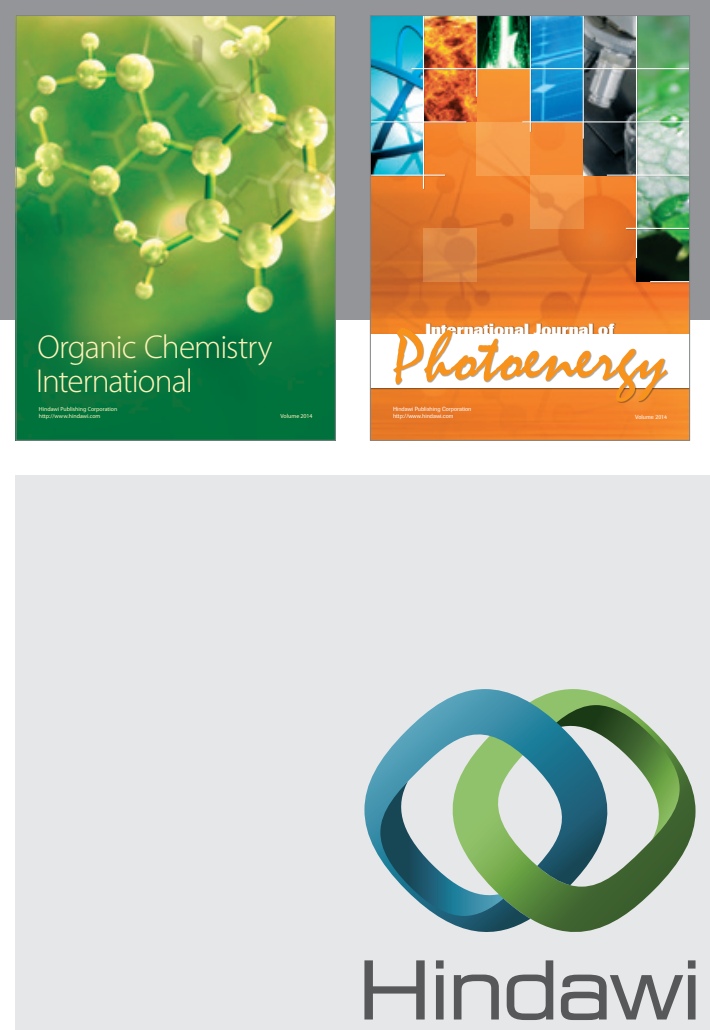

Submit your manuscripts at

http://www.hindawi.com
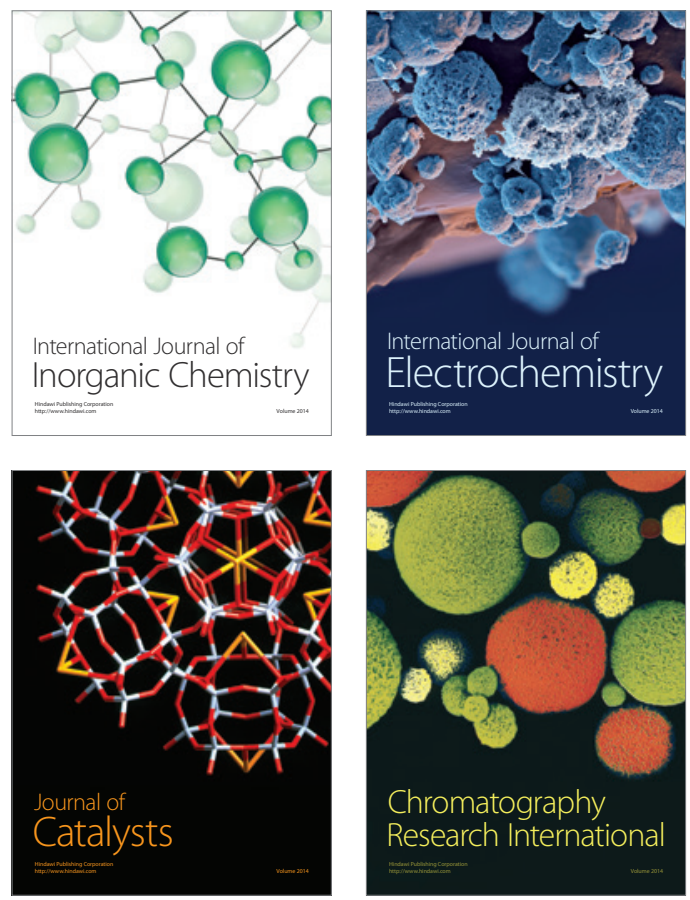
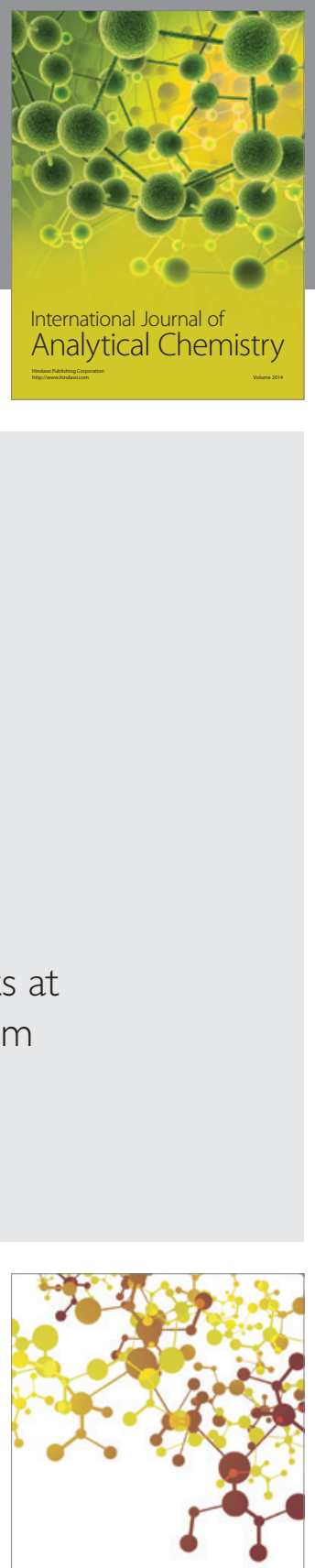

Journal of

Applied Chemistry
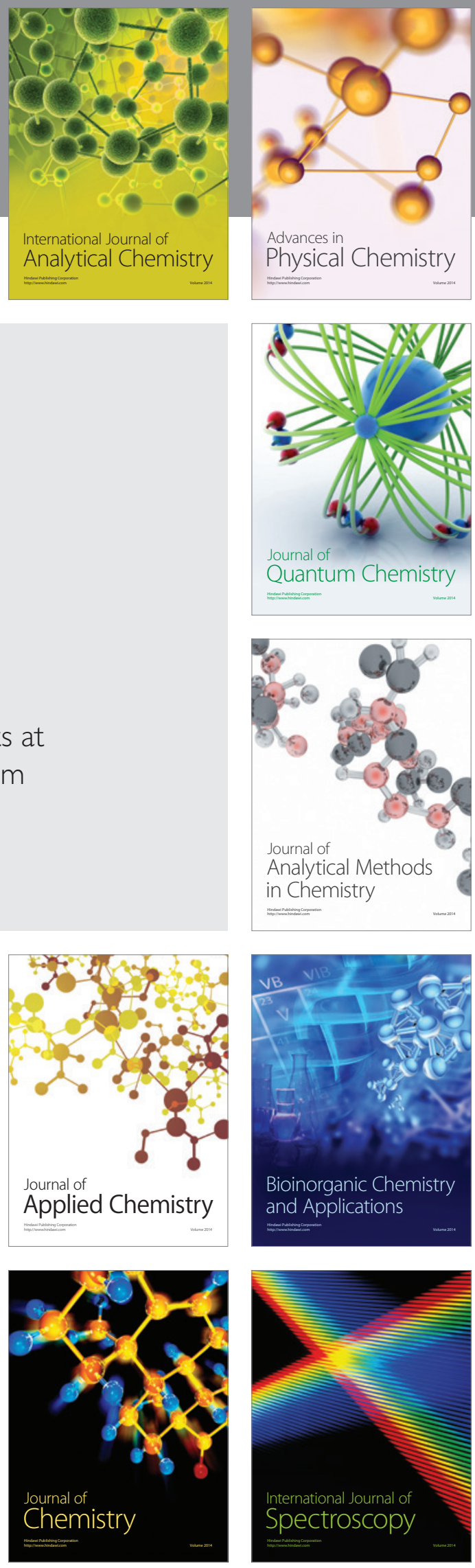